\title{
Contratos comunicativos e ação situada: uma abordagem pragmática
}

Ricardo Fabrino Mendonça

\section{Resumo}

0 presente artigo busca discutir o conceito de contrato comunicativo, explorando as bases e os contornos gerais da idéia. Criticando os enfoques que restringem o contrato a uma análise textual, bem como as abordagens excessivamente centradas no sujeito, realizamos uma leitura da noção que tem em seu cerne a idéia de situação comunicativa. Nessa trilha, buscaremos realizar uma aproximação entre a noção de contrato e a de ação situada, estabelecendo diálogo com uma tradição sociológica que remonta às conversações de Tarde, à reflexividade de Dewey e Mead, aos frames de Goffman e aos contextos institucionais de Quéré. 0 objetivo é chamar a atenção para a fertilidade do conceito de contrato se abordado a partir de um enfoque pragmático.

\section{Palavras-chave}

Contrato comunicativo. Ação situada. Frames.

\section{Ricardo Fabrino Mendonça | ricardofabrino@hotmail.com}

Doutorando em comunicação social pelo Programa de Pós-Graduação em Comunicação da Universidade Federal de Minas Gerais - UFMG. Bolsista da Fundação de Amparo à Pesquisa de Minas Gerais - FAPEMIG. Integra o Grupo de Pesquisa em Mídia e Espaço Público da UFMG e 0 Deliberative Democracy Group da ANU.

Agradeço a Vera França por sua valiosa contribuição na elaboração deste artigo. Também sou grato à FAPEMIG pelo apoio financeiro concedido ao pesquisador sob a forma de bolsa.

\section{Introdução}

A noção de contrato tem ganhado crescente atenção em pesquisas das áreas de lingüística e de comunicação social. Merecem destaque estudos preocupados com o chamado campo da recepção, análises voltadas para a apreensão do receptor nas próprias estruturas textuais de um bem simbólico e trabalhos orientados para avaliar as propostas interativas de um (ou mais) produto(s) de comunicação, sendo marcante, nestes últimos, a presença do conceito de gênero. ${ }^{1}$

0 pressuposto geral que alicerça tais estudos é 0 de que 0 ato comunicativo envolve uma espécie de pacto, que possibilita 0 estabelecimento da relação entre as instâncias interlocutivas.

A idéia é a de que a comunicação, seja ela midiatizada ou face-a-face, formal ou informal, escrita ou oral, depende de um acordo tácito que possibilita a própria instauração da interlocução e é atualizada por meio dela. Bastante rica, a perspectiva permite conceber a comunicação para além de um enfoque unilateralizante.

Operacionalizável, ela possibilita pensar uma abordagem complexa e relacional dos 
processos comunicativos, fomentando análises contextualizadas e sensíveis à atuação conjunta dos interlocutores.

É importante perceber, contudo, que a ampla utilização da noção de contrato não é despida de perigos. Algumas pesquisas permanecem muito presas ao texto, acabando por reduzir o processo comunicativo às materialidades simbólicas. ${ }^{2}$

Outras parecem encarar o contrato comunicativo a partir da mesma lógica do homônimo no campo jurídico e assumem que tal contrato é uma ação deliberada e consciente dos parceiros envolvidos.

0 objetivo do presente artigo é discutir 0 conceito de contrato em diálogo com alguns dos textos fundadores da noção. Pretende-se explorar os contornos gerais da idéia, de modo a extrair princípios importantes para a análise de fenômenos comunicativos. Criticando os enfoques que restringem 0 contrato a uma análise textual, bem como as abordagens excessivamente centradas no indivíduo, realizamos uma leitura da noção que tem em seu cerne a idéia de situação comunicativa. Nessa trilha, buscaremos realizar uma aproximação entre a noção de contrato e a de ação situada, estabelecendo diálogo com uma tradição sociológica que remonta a Tarde, Dewey, Mead, Goffman e Quéré. 0 objetivo é chamar a atenção para a fertilidade do conceito de contrato se abordado a partir de um enfoque pragmático.

\section{Contratos de comunicação: pactos relacionais}

A idéia de contrato de comunicação encontra suas raízes em três autores: Umberto Eco, Eliseo Verón e Patrick Charaudeau. De maneiras distintas, cada um deles buscou refletir sobre acordos tácitos que regem práticas comunicativas. Tais acordos permitem a ligação de interlocutores, ao mesmo tempo em que são gerados no próprio ato por meio do qual os sujeitos se ligam.

Umberto Eco desenvolve tal perspectiva sem fazer referência explícita ao termo contrato. Em seu clássico ensaio sobre o Leitor-Modelo, Eco (1986) aponta como 0 interlocutor-receptor atravessa a própria construção de uma forma simbólica, sendo previsto pelo texto e nele se inscrevendo. Um texto demanda e delineia seus receptores, prevendo quem são os interlocutores hábeis a cooperar para sua atualização. "0 Leitor-Modelo constitui um conjunto de condições de êxito, textualmente estabelecidas, que devem ser satisfeitas para que um texto seja plenamente atualizado no seu conteúdo potencial" (ECO, 1986, p. 45). 0 autor de um bem simbólico 
antecipa expectativas e lida com elas na própria geração do texto.

Com a imagem do Leitor-Modelo, Eco (1986) não deseja, todavia, eliminar a importância do leitor real. A interpretação depende dos movimentos cooperativos de um leitor concreto. 0 interlocutor-receptor tem um papel fundamental exatamente porque é capaz de atualizar os não-ditos do texto. Isso só pode ser feito porque existe uma trama tácita unindo os interlocutores. É ela que permitirá ao leitor compreender esses não-ditos, que são supostos pelo interlocutor-emissor. Também é ela que lhe permite hipostasiar um Autor-Modelo, cujos traços são inferidos a partir das estratégias textuais. Existe uma espécie de contrato subterrâneo que possibilita tanto a criação como a interpretação do texto.

Não se trata, obviamente, de um acordo transparente em que os não-ditos são estrategicamente silenciados por um emissor e limpidamente deduzidos pelo receptor. Eco (1986) percebe as opacidades das trocas comunicativas e destaca que os interlocutores podem operar com enciclopédias distintas. 0 leitor pode traçar trilhas distintas das previstas pelo autor, seja porque trabalha com outras referências, seja porque suas competências foram calculadas de modo insuficiente (ECO, 1986, p. 41). ${ }^{3}$
0 maior problema de Eco talvez seja a restrição de tal contrato às estruturas textuais. Seus insights são ricos, mas oferecem poucos operadores para que se analise a situação comunicacional de um modo mais amplo. Essa crítica também pode ser dirigida a Eliseo Verón, um dos precursores na defesa explícita de uma abordagem guiada pela idéia de contrato no campo dos estudos de linguagem.

Verón (2004) propõe uma análise de discurso orientada pela noção de contrato de leitura, atentando para a centralidade da enunciação. Para Verón, a maneira de dizer algo é tão importante como aquilo que é dito (VERÓN, 2004, p. 177). Ele afirma que, em cada discurso, as modalidades do dizer instauram um dispositivo de enunciação, que constitui a figura do enunciador e a do destinatário. Percebe, assim, de modo semelhante a Eco, que estes são entidades discursivas que se interpelam textualmente. "Pelo funcionamento da enunciação, um discurso constrói uma certa imagem daquele que fala (o emissor), uma certa imagem daquele a quem falamos (o destinatário) e, em conseqüência, um laço entre estes 'lugares"' (VERÓN, 1983, p. 3-4). E essa enunciação não é autônoma, mas produzida no interior do próprio contrato.

Verón (1983) reflete, particularmente, sobre os contratos de leitura constituídos por jornais 
impressos, que, em suas capas, imagens, diagramações, escolhas lexicais, classificações do material e propostas de percurso, estabelecem tipos singulares de laço com seus leitores. De acordo com o lingüista, os âmbitos de emissão e recepção de um jornal não podem ser abordados separadamente. Para Verón, periódicos que tratam de temáticas muito semelhantes podem ser muito diferentes, porque enunciam tais conteúdos de maneiras distintas, estabelecendo contratos díspares. 0 que caracteriza o contrato é a recorrência de determinadas modalidades discursivas, que podem delinear uma configuração mais ou menos coerente de uma publicação ou de um suporte. Configuração essa que afeta a leitura feita pelas pessoas. São os contratos que estabelecem o liame entre a materialidade simbólica e o leitor. Nesse sentido, para que uma publicação seja bem sucedida, ela deve dialogar com as expectativas, motivações e interesses compartilhados pelo público (VERÓN, 1983, p. 3). Verón (2004) defende, ainda, que a consumação de um contrato só ocorre no momento da leitura com o reconhecimento deste pelos receptores. "Um discurso é um espaço habitado, repleto de atores, de cenários, de objetos, e ler é 'colocar em movimento' esse universo [...]. Ler é fazer" (VERÓN, 2004, p. 181). Apreender as gramáticas de produção e as gramáticas de reconhecimento, bem como o funcionamento da circulação de um texto, é algo fundamental para captar seus efeitos.
Efeitos esses que não são causais e automáticos, mas se inserem em uma semiose que é "ternária, social, infinita, histórica" (VERÓN, 1980, p. 188).

Embora Verón proponha a ultrapassagem de perspectiva imanentista, defendendo uma abordagem social, sua visão do contrato permanece bastante centrada no texto. Ele continua lendo a enunciação na própria materialidade textual, nas escolhas e marcas que se manifestam por meio dela. Deixa escapar, assim, parte de seu insight, na medida em que foca as operações de investimento: a "colocação do sentido no espaço-tempo, sob a forma de processos discursivos" (1980, p. 191).

François Jost (2004) aponta exatamente essa questão, quando analisa o trabalho de Verón. 0 pesquisador francês critica a virtualidade dos sujeitos textuais, opondo-se à "consideração de que o contrato está no texto, dentro do texto" (JOST, 2004, p. 10). Atribuímos esse problema mais ao pioneirismo de Verón do que a uma não percepção das múltiplas relações sociais que atravessam e constrangem a tessitura de um texto. 0 autor parece mais preocupado em defender a própria idéia de contrato do que em aprofundá-la.

Uma abordagem mais articulada da noção, e menos restrita à dimensão textual da mesma, pode ser encontrada em Patrick Charaudeau (1996; 1997; 2006). 0 expoente da chamada Nova Análise de Discurso francesa ${ }^{4}$ tem se 
destacado na discussão da idéia de contrato

e na sua aplicação empírica a diversos

fenômenos comunicativos. Para Charaudeau, contratos regulam as expectativas recíprocas dos sujeitos comunicantes.

[...] toda troca linguageira se realiza num quadro de co-intencionalidade, cuja garantia são as restrições da situação de comunicação. 0 necessário reconhecimento recíproco das restrições da situação pelos parceiros da troca linguageira nos leva a dizer que estão ligados por uma espécie de acordo prévio sobre os dados desse quadro de referência (2006, p. 68).

Para 0 autor, é a existência de contratos de comunicação que possibilita e molda 0 intercâmbio linguageiro. A condição mínima de qualquer contrato é o reconhecimento recíproco dos sujeitos (CASTR0, 2003). Além de se reconhecerem, os parceiros precisam se embasar em um conjunto de referências comuns que permitam 0 estabelecimento do laço comunicativo.

Os atributos específicos de cada contrato variam em função da situação comunicativa. "A situação de comunicação é como um palco, com suas restrições de espaço, de tempo, de relações, de palavras, no qual se encenam as trocas sociais e aquilo que constitui o seu valor simbólico" (CHARAUDEAU, 2006, p. 67). Essas restrições (contraintes discursives) são regulações, convenções e normas que possibilitam a interlocução na medida em que a governam. Assim, "nem a produção, nem a recepção processam-se à revelia de restrições que devem ser impostas ao seu funcionamento" (MARI, 2002, p. 36).
Os contratos não representam, contudo, um completo cerceamento dos sujeitos. Contratos também são um espaço de abertura de campos de possibilidades estratégicas (stratégies discursives), demandando a ação dos sujeitos interlocutores. "0 espaço das estratégias discursivas representa a margem de manobra que o sujeito comunicante dispõe para executar seu projeto de fala" (COURA-SOBRINHO, 2003, p. 272).

A compreensão dos elementos constituintes de um contrato de comunicação requer, segundo Charaudeau, a consideração de um conjunto de dados fixos (externos e internos). Se se tem em vista que 0 discurso tem um componente lingüistico (material verbal) e um situacional (material psicosocial), que "são simultaneamente autônomos, em sua origem, e interdependentes em seu efeito" (CHARAUDEAU, 1996, p. 6), fica claro que os dados externos remetem ao componente situacional do discurso ao passo que os internos se referem ao componente linguístico.

Habituado a sub-categorizar suas categorias, Charaudeau (2006, p. 68-71) agrupa os dados externos que moldam um contrato em quatro condições: 1) A identidade dos interlocutores; 2) A finalidade das trocas estabelecidas; 3$) 0$ propósito ou dominio de saber de que se trata; $\mathrm{e}$ 4) 0 dispositivo e a ambiência que permitem a materialização da comunicação (CHARAUDEAU, 2006, p. 105). 0 autor defende que variações em qualquer um desses elementos instauram pactos interlocutivos diferentes. 
Os dados internos, por sua vez, também são subcategorizados "em três espaços de comportamentos linguageiros, a saber: 0 espaço de locução, 0 espaço de relação, o espaço de tematização" (CHARAUDEAU, 2006, p. 70). Nesses espaços, reside o ponto nodal de que tratam tanto Eco (1986) como Verón (1983). 0 espaço da locução diz respeito à justificativa da tomada da palavra pelo enunciador, que constrói uma imagem de si e identifica 0 interlocutor-destinatário. 0 espaço da relação refere-se ao tipo de laço estabelecido pelos interlocutores. Por fim, o espaço de tematização é aquele da organização do discurso (descritivo, argumentativo, narrativo), dadas as possibilidades de uma certa situação.

Importante ressaltar que, na perspectiva de Charaudeau, os contratos comunicativos não estão inteiramente dados e nem são estáticos.

Eles se constroem e se atualizam nas próprias relações ao mesmo tempo em que as in-formam.

Se produzir um discurso é inserir-se em uma rede de intertextualidades, como assinala Charaudeau (1996), é preciso perceber que a proposta vislumbra tanto um diálogo com quadros de referência já existentes como uma inserção ativa nesses quadros. É na própria proferição de um ato de linguagem que se define a "relação de lugares de ambas as partes [e se apresenta] um pedido de reconhecimento do lugar que cada um vê lhe ser atribuído"

(MAINGUENEUAU, 1996, p. 10).

Assim como Verón, Charaudeau (1997; 2006) dedica grande parte do seu trabalho à análise de contratos estabelecidos pelos meios de comunicação. Ele propõe uma abordagem atenta às interfaces entre as instâncias de produção e de recepção. Cada uma destas se configura simultaneamente como agência social e agência discursiva, ou, nas palavras de Charaudeau (1996; 2006), como parceiros (Sujeito comunicante $\mathrm{X}$ Sujeito Interpretante) e protagonistas (Sujeito Enunciador X Sujeito Destinatário). ${ }^{5}$

Apesar da riqueza dessa perspectiva, e contradizendo os próprios alicerces de sua teoria, Charaudeau afirma que não há troca efetiva entre as instâncias de produção e recepção: "Por mais que as mídias recorram a técnicas ditas interativas, não há diálogo e troca, somente 0 seu simulacro" (2006, p. 124). Ele diz tratar-se de um discurso unidirecional, cujo poder reside na influência. Charaudeau parece, desse modo, negar o primado da interação que está na base de sua abordagem. Ele negligencia a configuração relacional do contrato que embasa a inserção dos interlocutores no ato comunicativo.

Com isso, fortalece os argumentos de certos críticos da noção de contrato, como François

5 Para o autor, "a instância de produção deve ser considerada de modo diferente, ora como organizadora do conjunto do sistema de produção, num lugar externo, ora como organizadora da enunciação discursiva da informação" (2006, p. 72). Do mesmo modo a "instância de recepção também deve ser desdobrada: de um ponto de vista interno à instância midiática, é designada como destinatário - a 'instância-alvo'; de um ponto de vista externo, como instância de recepção propriamente dita, com uma atividade própria de consumo, é designada como 'instância-público” (idem, p. 72-3). 
Jost. Em seus estudos sobre a televisão, Jost (2004) alega que o fenômeno midiático é tão repleto de incertezas que não se pode falar de acordo tácito. Ele restringe o contrato ao que chama comunicação recíproca e afirma que tal reciprocidade não seria possível na televisão. No lugar do contrato, Jost (2004) propõe uma abordagem norteada pela idéia de promessa, a qual ocorreria em dois tempos: 0 da enunciação e 0 de sua posterior verificação pelos interlocutores-receptores.

A grande diferença da proposta de Jost é a da distensão temporal do processo em dois momentos. Com isso, no entanto, Jost mina as próprias bases pragmáticas do contrato, que nos parecem a dimensão mais rica do conceito. Ele esvazia o sentido da atualização em ato de um acordo tácito e acaba por re-conduzir a uma leitura centrada nos atores: a instância midiática que promete e a audiência que avalia. Como Charaudeau, ele deixa escapar a dialogicidade da comunicação midiática. Ainda que Jost deseje exatamente 0 oposto, sua proposta pode fortalecer perspectivas calcadas no individualismo metodológico, ao negligenciar a intersubjetividade que funde esses dois momentos.

Além disso, Jost (2004) assume uma premissa contestável: a de que os media elaboram seus discursos em um campo muito mais incerto do que o da comunicação face-a-face. Não necessariamente. Tal premissa só faz sentido se 0 ato comunicativo for recortado do seu contexto mais amplo. Se se analisa o fenômeno puramente em termos de 'como falar para muita gente ao mesmo tempo?', a observação parece plausível. Mas, quando se percebe 0 profundo imbricamento social dos media, com uma história de interlocuções travadas que comunalizam padrões interpretativos, nota-se que esse aumento da audiência pode exatamente reduzir incertezas e solidificar pactos.

\section{Para além do texto e dos atores, a situação}

Entendemos que grande parte dos problemas da noção de contrato advém dos seus desenvolvimentos e aplicações, que acabam por complexificar uma idéia bastante simples. Acreditamos que a riqueza do contrato está no foco que ela coloca sobre a situação comunicativa. Calcada em pressupostos pragmáticos, a perspectiva evidencia que a interação social só se realiza em ato, sendo atravessada por uma série de variáveis que se combinam de modos específicos a cada interação. A compreensão do contrato, nesse sentido, ultrapassa os aspectos discursivos de uma interação e as intencionalidades dos interlocutores. 0 contrato está calcado em um acordo que não é consciente, nem inteiramente formulado na textualidade.

0 contrato comunicativo, com suas parametragens contextuais, alicerça-se sobre memórias intersubjetivamente partilhadas e que atravessam 0 ato comunicativo. Em cada situação, 
essas memórias se articulam de modos específicos, balizando as relações estabelecidas entre sujeitos (SOUZA, 2003). A situação comunicativa é, portanto, elemento estruturante de sua prática.

Essa preocupação de entender a interação comunicativa dentro de sua situação de ocorrência remonta a várias correntes de estudo, que se aproximam em virtude de suas orientações microssociológicas e pragmatistas. Já Gabriel Tarde, no início do século XX, foi capaz de tratar a noção de conversação de uma maneira refinada e contextualizada. Embora restrinja a conversação aos diálogos em que se fala por falar, por prazer, por distração, ou por polidez (TARDE, 1992, p. 95), em uma definição que se aproxima do conceito simmeliano de sociabilidade, Tarde percebe que mesmo esse tipo específico de interação pode assumir facetas variadas em distintos contextos. Há conversações marcadas pela maior ou menor simetria entre os participantes, conversações obrigatórias ou facultativas, formais e informais, simultâneas a outras atividades ou não. Para 0 autor, essas variações não são resultado de simples escolhas dos interlocutores. 0 autor assinala que até mesmo a velocidade com que falamos é fruto da sociedade em que vivemos e que os elementos situacionais são centrais no desenrolar de uma conversa. Evidencia-se, dessa maneira, que há acordos sociais subjacentes às trocas linguageiras. Já estão insinuadas as idéias centrais à noção de contrato.
Os autores da escola de Palo Alto também serão propagadores da necessidade de uma interpretação contextualizada das ações sociais, aí se inscrevendo as trocas comunicativas. Buscando compreender a natureza de distúrbios psíquicos, Watzlawick et al (1967) sugerem que se pense a interação no interior de uma sequiência ininterrupta de trocas, que é marcada por um processo permanente de organização. "Culturalmente, compartilhamos de muitas convenções de pontuação que [...] servem para organizar comuns e importantes seqüências de interação" (WATZLAWICK et al, 1967, p. 51). Deixam claro, assim, que a comunicação é regida por regras implícitas e naturalizadas, que são atualizadas e testadas no próprio momento da interação.

Antes dos autores de Palo Alto, dois dos chamados pais fundadores do pragmatismo, Dewey e Mead, já percebiam a importância de se situar a interação em uma cadeia de relações sociais, atentando para as regras que a precedem, mas que são reflexivamente retomadas no momento em que são mobilizadas. A começar por Mead (1934), lembramos que ele atenta para a importância de se pensar a ação dos sujeitos em seu contexto. Ele propõe pensar as ações não a partir da suposição das causas que as motivaram, mas da observação de sua materialização em uma situação interativa. Percebe, assim, que os sujeitos engajados em uma troca simbólica estão envoltos por laços sociais que se traduzem em expectativas recíprocas e padrões de comportamento atualizados no próprio ato da 
interação. Há, portanto, uma espécie de acordo tácito, que se manifesta na interação.

Para explicar essa questão, Mead (1934) recorre à noção de Outro Generalizado, conceito que se refere ao social pensado de maneira universal. Em sua trajetória de experiências sociais, os sujeitos são socializados, internalizando padrões, regras e parâmetros interativos. Na sucessão de encontros com os outros, aprendem o que se espera deles e o que podem esperar dos outros em determinadas situações. Assim, a cada interação, passam a operar com essas balizas. A edificação da ação é guiada pela reflexividade que envolve uma relação tríplice: 1) do gesto com o próprio ator que o executa; 2) do gesto com o outro; e 3) do gesto em seus desdobramentos. Para Mead (1934), a reflexividade é uma espécie de ponderação; uma ação de ligação entre o gesto e 0 significado que conduz à interposição (entre estímulo e resposta) de uma organização. Os seres humanos selecionam e organizam estímulos, refletem sobre alternativas e fazem escolhas interativamente.

Mead trabalha essa idéia de reflexividade em estreito diálogo com o pensamento de John Dewey. Ao discorrer sobre o conceito de público, Dewey (1954) evidencia a existência de um misto de sofrer e reagir: "aqueles indireta e seriamente afetados, por bem ou por mal, formam um grupo suficientemente distinto para merecer um nome. 0 nome escolhido é Público" (DEWEY, 1954, p. 35). Esse grupo não apenas $\boldsymbol{e}$ afetado pelos efeitos de algo, mas se posiciona e responde a eles. Segundo
Dewey, o público é diferente da massa porque tem a percepção daquilo que 0 afeta e age sobre essa afetação. Tal resposta é formulada não como uma reação mecânica, mas no interior de um arco-reflexivo, em que a resposta interfere no estímulo antes mesmo que ele se produza. Nessa perspectiva pragmatista, o público aparece como um tipo de associação efêmera e contingente que só se realiza no momento em que age. Ou seja, ele só se configura situacionalmente, sendo moldado e conformado por elementos contextuais, ao mesmo tempo em que age sobre eles. É a situação que oferece um leque de restrições que se impõem aos sujeitos, mas é essa mesma situação que lhes abre campos de possibilidades para que ajam de forma criativa e reflexiva.

Embora Tarde, Watzlawick, Mead e Dewey ofereçam insights fundamentais para pensar 0 caráter situado da ação, é sem dúvida Goffman quem mais desenvolve essa idéia. Herdeiro da Escola de Chicago e em diálogo com os pesquisadores de Palo Alto, Goffman sempre se dedicou ao estudo das interações sociais de um modo contextualizado. Suas descrições perspicazes examinam seqüências (strips) interativas com profundidade, permitindo o mapeamento de diversas formas de relação social.

Seu enfoque não busca, todavia, uma incontável enumeração descritiva de situações. Como ele mesmo explica, seu projeto acadêmico voltou-se para captar a ordem da interação; ou seja, os padrões, regras e procedimentos que 
conduzem as ações reciprocamente referenciadas (GOFFMAN, 1999). Esteja ele preocupado com as interações corriqueiras e ordinárias (GOFFMAN, 1986; 1996), com as práticas e adaptações secundárias de internos de instituições totais (GOFFMAN, 2003) ou com o modo como os sujeitos manipulam seus atributos e identidades de modo a lidar com certos estigmas (GOFFMAN, 1988), há sempre uma busca pelos parâmetros que regulamentam e regem a interação social.

Nessa perspectiva, os atores sociais não são inteiramente autônomos e independentes, mas são o resultado de determinadas situações. Se não se pode negligenciar a importância da agência dos indivíduos, é preciso perceber que essa só ganha corpo em determinadas situações que estabelecem balizas e parâmetros, porque atravessadas por acordos prévios e intersubjetivos. Na microssociologia de Goffman, "não é o indivíduo que constitui a unidade elementar da pesquisa, mas a situação" (JOSEPH, 2000, p. 10-11). Assim, o contexto atua como um quadro ordenador da experiência.

Esse é 0 aspecto centralmente trabalhado por Goffman (1986) em Frame Analysis, obra em que ele se volta para o conceito de Frames (quadros) proposto por Gregory Bateson. Em Goffman, a idéia de frame refere-se às estruturas que organizam a percepção da realidade e a ação dos sujeitos no mundo. 0 conceito tem, portanto, uma dimensão cognitiva e uma prática. Trata-se de princípios estruturadores (ready-made interpretativos), que atuam como esquemas, orientando a compreensão do mundo e 0 engajamento dos sujeitos em situações específicas (GOFFMAN, 1986, p. 345).

Esses parâmetros não verbalizados são a condição de possibilidade da própria interação, sendo continuamente testados. A competência comunicativa é o conhecimento das regras e do uso adequado delas. Goffman (1986) aponta que essa competência também envolve reparações e a contínua adaptação mútua, em uma espécie de permanente alinhamento de quadros. Os sujeitos coordenam e organizam suas interações continuamente, sendo que é 0 teste intersubjetivo que permite a aplicação e a atualização das regras.

Mas qual a relação entre a noção goffmaniana de frames e os contratos comunicativos que vínhamos abordando na primeira seção do texto? A noção de quadros, com seu foco na ação situada, traz consigo a própria idéia de contrato, expandindo-a para além de textos e da consciência dos sujeitos. Ela diz desses acordos não explícitos que fundam 0 ato de linguagem, porque incluem sua possibilidade de validação (MAINGUENEAU, 2002, p. 69).

Para Goffman, a conversação está assentada em um acordo que 0 sujeito estabelece com os outros e consigo mesmo e que é dado pela situação. É por isso que ele indica uma profunda relevância deframes na organização da fala (1986, p. 511). Os interlocutores estão, desde o início de qualquer 
interação comunicativa, ligados por conjuntos de regras, padrões interpretativos e expectativas recíprocas que consideram socialmente partilhados. Para interagir, eles precisam definir a situação em que se encontram, e essa definição não é criada pelos atores engajados na interação, mas provém de frames socialmente partilhados.

São esses quadros que permitem ao enunciador organizar o enunciado, tendo em vista aquele a quem ele fala. Eles restringem as possibilidades de ação do enunciador, delineiam imagens de destinatários e abrem campos estratégicos para que 0 enunciador faça suas escolhas e percursos. Do mesmo modo, também o interlocutorreceptor age a partir dos parâmetros colocados peloframe. São tais quadros que permitem a destinatários interpretar enunciados e atribuí-los a determinados atores. Ainda que os interlocutores possam operar com quadros distintos, 0 estabelecimento da relação comunicativa necessita de um acordo mínimo capaz de vinculá-los.

Os quadros funcionam, assim, como um terreno intersubjetivo tácito que emoldura e possibilita a interação, manifestando-se por meio delas. No capítulo em que propõe uma frame analysis da conversação, Goffman (1986) frisa que a enunciação só se constrói em um ambiente e que retirá-la de seu contexto é torná-la incompreensível. Como também reconhecem Charaudeau (2006) e Verón (1980), a situação comunicativa delineia as possibilidades de desenvolvimento das trocas comunicativas, ainda que 0 efetivo desenrolar desta só se realize no próprio ato do interagir. Os interlocutores precisam construir imagens recíprocas para estabelecer uma interação, sendo que essas imagens só podem ser construídas se existem quadros socialmente partilhados, que lhes permitem compreender o que está acontecendo e que opções de agência estão disponíveis.

No entanto, diferentemente da proposta de Eco (1986) e da de Verón (1983), a perspectiva de Goffman (1986) permite-nos perceber que esses enunciadores e destinatários são não apenas papéis actanciais construídos pelo texto. Se é preciso reconhecê-los como estratégias textuais, é fundamental vê-los também como actantes fora do texto. Charaudeau (1996) já segue nessa direção quando assinala que a relação comunicativa envolve, simultaneamente, inter- e intra-locutores. Os actantes se conformam na própria interação comunicativa, materialiazada no texto, mas que joga para fora dele.

Vera França (2006) trabalha esse aspecto em artigo que procura definir quem são os sujeitos da comunicação e qual é a ação que os constitui. De acordo com ela, o "sujeito da comunicação ou em comunicação [...] nomeia um sujeito enredado numa teia de relações. São as relações que constituem esse sujeito" (FRANÇA, 2006, p. 76-77). Relações essas que são estabelecidas e balizadas pelos quadros socialmente partilhados. Tais frames articulam os sujeitos em comunicação, que são pensados 
como actantes para além do texto que os vincula momentaneamente. Imersos em uma teia de relações, esses sujeitos tornam-se agentes em um processo mais amplo que não começa nem termina com 0 enunciado e que é regido por pressupostos normativos partilhados.

Remetendo diretamente a Goffman, França (2006, p. 79) aponta que as interações são ordenadas pelo contexto, "fundadas em expectativas recíprocas" e mutuamente coordenadas. Como se nota, está em questão uma abordagem atenta à situação, à prática dos sujeitos e à interação que estabelecem. 0 desempenho dos indivíduos constitui-se em ato, na situação comunicativa, sendo orientado pela ordem da interação, para usar os termos de Goffman (1999) Ordem essa que atua como um contrato, permanentemente firmado e atualizado nas situações interativas.

Nesse sentido, o questionamento da noção de contrato feito por Guimarães (1999, p. 116), que "insist[e] em perguntar como e quando ele é firmado", não nos parece muito frutífero. Tais respostas só podem ser respondidas contextualmente porque esses acordos intersubjetivos são firmados, refeitos e atualizados no próprio ato da interação. Tais pactos subterrâneos podem ser cristalizados, fortalecidos ou derrubados na medida em que os quadros que permitem a interação mostram-se úteis, ou não, para o estabelecimento do vínculo com o outro.

Pensar a noção de contrato no campo da comunicação requer, pois, ultrapassar as análises centradas em textos (materialidades simbólicas) e em indivíduos. 0 contrato não é firmado por sujeitos conscientes, nem existe inteiramente em sua inscrição textual. Ele é colocado em cena pela situação comunicativa e atua, como um contexto institucional, como percebe Quéré (2003): um conjunto de regras, formatos, padrões e modelos partilhados que orientam a ação dos sujeitos e criam suas condições de possibilidade. "Esse contexto, que fornece as regras de comportamento, releva de uma ordem do sentido instituído" (QUÉRÉ, 2003, p. 121). É esse contexto institucional que pauta a ação dos sujeitos.

Nessa perspectiva, os indivíduos não podem ser tomados como o elemento central e definidor das ações. Ao contrário, como indica Quéré (2003), eles são configurados pela ação, devendo ser compreendidos como advérbios. "0 sujeito não é ele mesmo mais que um complemento do verbo: como os advérbios, ele completa 0 verbo ao precisar uma modalidade de ação expressa por ele" (QUÉRÉ, 2003, p. 126). É a ação, moldada por uma dada situação, que demanda determinada forma de agência dos sujeitos e os orienta. Nessa visão, a ação discursiva é precedida pela situação relacional que a conforma.

\section{Considerações finais}

0 presente artigo buscou analisar a noção de contrato que vem sendo bastante utilizada no campo da comunicação. Iniciamos com a apresentação das propostas de Eco (1986), Verón 
(1980; 1983; 2004) e Charaudeau (1996; 1997; 2006). Em seguida, buscamos discutir quão frutífero tal conceito pode ser se pensado à luz da idéia de $a c ̧ a ̃ o$ situada. Para tanto, exploramos uma tradição de pesquisa pragmatista que remonta a Gabriel Tarde (1992), à Escola de Palo Alto, a Mead (1934) e a Dewey (1954). Detivemo-nos, com mais vagar, na proposta de frames elaborada por Goffman (1986) e concluímos com uma breve menção aos insights apresentados por Quéré (2003).

0 objetivo desse trajeto foi evidenciar que a situação comunicativa é um elemento central para qualquer análise de interações comunicacionais. Isso não apenas porque tal situação é mais uma variável no desenrolar dessas interações, mas porque criam as próprias condições de sua possibilidade, mobilizando quadros partilhados que são essenciais para seu estabelecimento. Como lembra Lucília Marcos (1995, p. 42), em análise do trabalho de Francis Jacques, o contexto comunicativo envolve não só os aspectos circunstanciais da enunciação (como tempo e espaço), mas também as pressuposições e expectativas que 0 atravessam. E essas pressuposições partilhadas são indispensáveis para a validação local dos enunciados.

Ressaltamos que essa concepção de contrato, norteada pela idéia de frames e pela de contextos institucionais, pode mostrar-se extremamente rica em pesquisas empíricas, visto que tal perspectiva fomenta a captação da interação social na medida em que vislumbra o terreno comum criado e atualizado pelos interlocutores. Embora não tenhamos espaço, no presente artigo, para discorrer sobre a aplicação dessa noção no estudo dos media, salientamos tratarse de um veio muito frutífero. Se Goffman e Mead permanecem muito presos às interações face-a-face e Charaudeau (2006) negligencia, em certa medida, a relação interativa estabelecida pelos media, é preciso extrair os insights presentes nas teorias deles, projetandoos para a compreensão das relações entre media e sociedade. Tal tarefa requer analisar os discursos midiáticos não como enunciados isolados, mas como partes de uma tessitura social mais ampla. Tessitura essa que impõe seus limites a cada enunciado, mas que também abre infindáveis possibilidades a cada instante.

\section{Referências bibliográficas}

CASTR0, Maria Helena Steffens de. A encenação discursiva da publicidade. In: CONGRESSO ANUAL EM CIÊNCIA DA COMUNICAÇÃO. 26., 2003, Belo Horizonte. Anais... Belo Horizonte: INTERCOM, 2003. Disponível em: < http://www.intercom.org.br/papers/ nacionais/2003/www/pdf/2003_NP03_castro.pdf>. Acesso em: 05/07/2007.

CHARAUDEAU, Patrick. Discurso das mídias. São Paulo: Contexto, 2006.

CHARAUDEAU, Patrick. Le discours d'information médiatique - La construction du miroir social. Paris : Nathan, 1997.

CHARAUDEAU, Patrick. Para uma nova análise do discurso. In: CARNEIRO, A. D. (org.). 0 discurso da mídia. Rio de Janeiro: Oficina do autor, 1996. p. 05-43. 
COURA-SOBRINHO, J. Discurso, sujeitos da linguagem e contrato de comunicação. In: MARI, H. et al. Análise do discurso em perspectivas. Belo Horizonte: FALE/ UFMG, 2003. p. 267-279.

DEWEY, John. The public and its problems. Chicago: The Swallon Press, 1954.

DUARTE, Elizabeth Bastos; CASTRO, Maria Lilia Dias de. Comunicação audiovisual: gêneros e formatos. Porto Alegre: Sulina, 2007.

ECO, Umberto. 0 leitor modelo. In: Lector in fabula: a cooperação interpretativa nos textos narrativos. São Paulo: Perspectiva, 1986. p. 35-49.

FERREIRA, Giovandro Marcus. Uma proposta metodológica para 0 estudo da imprensa a partir das mutações na problemática da análise do discurso.

Revista de Economía Política de las Tecnologías de la Información y Comunicación (www.eptic.com.br), v. 8, n. 1, p. 1-15, jan.-abr. 2006.

FRANÇA, Vera. Sujeitos da comunicação, sujeitos em comunicação. In: GUIMARÃES, César;

Na mídia, na rua: narrativas do cotidiano. Belo Horizonte: Autêntica, 2006. p. 60-88.

GOFFMAN, Erving. A ordem da interação. In:

Os momentos e os seus homens. Lisboa: Relógio d’Água, 1999.

GOFFMAN, Erving. A representação do eu na vida cotidiana. 7. ed. Petrópolis: Vozes, 1996.

GOFFMAN, Erving. Estigma: notas sobre a manipulação da identidade deteriorada. 4. ed. Rio de Janeiro: LTC, 1988.

GOFFMAN, Erving. Manicômios, prisões e conventos. 7. ed. São Paulo: Perspectiva, 2003.

GOFFMAN, Erving. Frame analysis: an essay on the organization of experience. York: The Mapple Press, 1986. p. 1-155; 345-377; 496-559.
GOMES, Itânia. Efeito e recepção: a interpretação do processo receptivo em duas tradições de investigação sobre os media. Rio de Janeiro: E-Papers, 2005.

GUIMARÃES, César. Algumas notas sobre a interlocução entre a análise do discurso e a teoria da comunicação. In: MARI, Hugo et. al. Fundamentos e dimensões da análise do discurso. Belo Horizonte: Carol Borges, 1999. p. 107-121.

JOSEPH, Isaac. Erving Goffman e a microssociologia. Rio de Janeiro: FGV, 2000.

JOST, François. Comunicação televisual. In: DUARTE, M. B.; CASTRO, M. L. D. (org). Seis lições sobre televisão. Porto Alegre: Sulina, 2004. p. 9-26.

MAINGUENEAU, Dominique. Noções de pragmática. In: Pragmática para o discurso literário.

São Paulo: Martins Fontes, 1996. p. 01-28.

MAINGUENEAU, Dominique. Análise de textos de comunicação. São Paulo: Cortez, 2002.

MARCOS, Maria Lucília. Um estudo pragmático da comunicação. Comunicabilidade e comensurabilidade dos discursos. Revista de Comunicação e Linguagens, n.21-22, p. 35-55, 1995.

MARI, Hugo. Percepção do sentido: entre restrições e estratégias contratuais. In: MACHADO, I. L. et al. Ensaios em análise do discurso. Belo Horizonte: Fale/UFMG, 2002. p. 31-57.

MEAD, George Herbert. Mind self and society from the standpoint of a social behaviorist. Edição: Charles W. Morris. Chicago: University of Chicago, 1934.

NATANSOHN, L. Graciela. 0 contrato de leitura, uma metodologia para analisar a recepção de TV. ENCONTRO ANUAL DA ASSOCIAÇÃO NACIONAL DOS PROGRAMAS DE PÓS-GRADUAÇÃO EM COMUNICAÇÃO. 14., 2005, Niterói. Anais... Niterói: Compós, 2005. CD-ROM. 
OLIVEIRA, Ieda. 0 contrato de comunicação

da literatura infantil e juvenil. Rio de Janeiro:

Lucerna, 2003.

QUÉRÉ, Louis. Le public comme forme et comme modalité d'expérience. In: CEFAÏ, D ; PASQUIER, D. (org.) Le sens du publi: publics politiques, publics médiatiques. Paris: PUF, 2003. p.113-134.

SOUZA, Wander Emediato de. Os gêneros discursivos como tipos situacionais. In: MARI, H. et al. Análise do discurso em perspectivas. Belo Horizonte: FALE/ UFMG, 2003. p. 63-72.

TARDE, Gabriel. A opinião das massas. São Paulo: Martins Fontes, 1992. p. 29-154.

VERÓN, Eliseo. Cuando leer es hacer: la enunciación en el discurso de la prensa gráfica. In:

Fragmentos de un tejido. Barcelona: Gedisa, 2004. p. 171-191.

VERÓN, E. Lanalyse du 'contrat de lecture': pour une nouvelle méthode pour les études depositionnement des supports presse. Les médias, expériences, recherches actuelles, applications. Tradução: Áurea Pitta. Paris: IREP, 1983. Mimeo.

VERÓN, E. A semiose social. In: . A produção do sentido. São Paulo: Cultrix, 1980. p. 173-204.

WATZLAWICK, Paul; BEAVIN, Janet Helmick; JACKSON, Don D. Pragmática da comunicação humana: um estudo dos padrões, patologias e paradoxos da interação. São Paulo: Cultrix, 1967. 


\section{Communicative contracts and situated action: a pragmatic approach}

\section{Abstract}

This paper discusses the concept of communicative contract, exploring its basis and its general outlines. It criticizes both the approaches that restrict the contract to a textual analysis and that are excessively focused on the subject, as it proposes an understanding of the notion of contract guided by the idea of communicative situation. In this track, the paper promotes a connection between the notions of contract and situated action, establishing dialogue with a sociological tradition that goes back to Tarde's conversations, Mead's and Dewey's reflexivity, Goffman's frames and Quéré's institutional contexts. The paper aims to draw attention to the fruitfulness of the concept of contract, once it is conceived through a pragmatic approach.

\section{Keywords}

Communicative contract. Situated action. Frames.

\section{Contratos comunicativos y acción situada: un enfoque pragmático}

\section{Resumen}

Este artículo quiere discutir el concepto de contrato comunicativo, explorando las bases generales y los contornos de esta idea. Criticando los enfoques que restringen el contrato a un análisis textual y los enfoques demasiado centrados en el individuo, llevamos a cabo una lectura del concepto que tiene en su centro la idea de situación comunicativa. Por esta vía, procuramos lograr un acercamiento entre el concepto de contrato y el de acción situada, haciendo dialogar una tradición sociológica basada en la noción de conversaciones de Tarde, en la reflexividad de Dewey y Mead, en los frames de Goffman y en los contextos institucionales de Quéré. El objetivo es llamar la atención a la fertilidad del concepto de contrato en caso de abordarse desde un enfoque pragmático.

\section{Palabras clave}

Contrato comunicativo. Acción situada. Frames. 


\section{Expediente}

A revista E-Compós é a publicação científica em formato eletrônico da Associação Nacional dos Programas de Pós-Graduação em Comunicação (Compós). Lançada em 2004, tem como principal finalidade difundir a produção acadêmica de pesquisadores da área de Comunicação, inseridos em instituições do Brasil e do exterior.
E-COMPÓS I www.e-compos.org.br I E-ISSN 1808-2599

Revista da Associação Nacional dos Programas de Pós-Graduação em Comunicação. Brasília, v.11, n.2, maio/ago. 2008

A identificação das edições, a partir de 2008 passa a ser volume anual com três números.

\section{CONSELHO EDITORIAL}

\section{Afonso Albuquerque}

Universidade Federal Fluminense, Brasil

Alberto Carlos Augusto Klein

Universidade Estadual de Londrina, Brasi

Alex Fernando Teixeira Primo

Universidade Federal do Rio Grande do Sul, Brasi

Alfredo Vizeu

Universidade Federal de Pernambuco, Brasil

Ana Carolina Damboriarena Escosteguy

Pontifícia Universidade Católica do Rio Grande do Sul, Brasil

Ana Silvia Lopes Davi Médola

Universidade Estadual Paulista, Brasil

André Luiz Martins Lemos

Universidade Federal da Bahia, Brasil

Ângela Freire Prysthon

Universidade Federal de Pernambuco, Brasi

Antônio Fausto Neto

Universidade do Vale do Rio dos Sinos, Brasil

Antonio Carlos Hohlfeldt

Pontifícia Universidade Católica do Rio Grande do Sul, Brasil

Arlindo Ribeiro Machado

Universidade de São Paulo, Brasil

César Geraldo Guimarães

Universidade Federal de Minas Gerais, Brasi

Cristiane Freitas Gutfreind

Pontifícia Universidade Católica do Rio Grande do Sul, Brasi

Denilson Lopes

Universidade Federal do Rio de Janeiro, Brasil

Eduardo Peñuela Cañizal

Universidade Paulista, Brasil

Erick Felinto de Oliveira

Universidade do Estado do Rio de Janeiro, Brasil

Francisco Menezes Martins

Universidade Tuiuti do Paraná, Brasil

Gelson Santana

Universidade Anhembi/Morumbi, Brasil

Hector Ospina

Universidad de Manizales, Colômbia

leda Tucherman

Universidade Federal do Rio de Janeiro, Brasil

Itania Maria Mota Gomes

Universidade Federal da Bahia, Brasil

Janice Caiafa

Universidade Federal do Rio de Janeiro, Brasil

Jeder Silveira Janotti Junior

Universidade Federal da Bahia, Brasil
John DH Downing

University of Texas at Austin, Estados Unidos

José Luiz Aidar Prado

Pontifícia Universidade Católica de São Paulo, Brasil

José Luiz Warren Jardim Gomes Braga

Universidade do Vale do Rio dos Sinos, Brasi

Juremir Machado da Silva

Pontifícia Universidade Católica do Rio Grande do Sul, Brasil

Lorraine Leu

University of Bristol, Grã-Bretanha

Luiz Claudio Martino

Universidade de Brasília, Brasil

Maria Immacolata Vassallo de Lopes

Universidade de São Paulo, Brasil

Maria Lucia Santaella

Pontifícia Universidade Católica de São Paulo, Brasil

Mauro Pereira Porto

Tulane University, Estados Unidos

Muniz Sodre de Araujo Cabral

Universidade Federal do Rio de Janeiro, Brasil

Nilda Aparecida Jacks

Universidade Federal do Rio Grande do Sul, Brasil

Paulo Roberto Gibaldi Vaz

Universidade Federal do Rio de Janeiro, Brasil

Renato Cordeiro Gomes

Pontifícia Universidade Católica do Rio de Janeiro, Brasil

Ronaldo George Helal

Universidade do Estado do Rio de Janeiro, Brasil

Rosana de Lima Soares

Universidade de São Paulo, Brasil

Rossana Reguillo

Instituto Tecnológico y de Estudios Superiores do Occidente, México

Rousiley Celi Moreira Maia

Universidade Federal de Minas Gerais, Brasil

Sebastião Carlos de Morais Squirra

Universidade Metodista de São Paulo, Brasil

Simone Maria Andrade Pereira de Sá

Universidade Federal Fluminense, Brasil

Suzete Venturelli

Universidade de Brasília, Brasil

Valério Cruz Brittos

Universidade do Vale do Rio dos Sinos, Brasil

Veneza Mayora Ronsini

Universidade Federal de Santa Maria, Brasil

Vera Regina Veiga França

Universidade Federal de Minas Gerais, Brasil
COMISSÃO EDITORIAL

Ana Gruszynski I Universidade Federal do Rio Grande do Sul, Brasil João Freire Filho I Universidade Federal do Rio de Janeiro, Brasil Rose Melo Rocha I Escola Superior de Propaganda e Marketing, Brasil

\section{CONSULTORES AD HOC}

Aníbal Bragança I Universidade Federal Fluminense, Brasil Gisela Castro I Escola Superior de Propaganda e Marketing, Brasil

Gislene Silva I Universidade Federal de Santa Catarina, Brasil

Maria Helena Weber I Universidade Federal do Rio Grande do Sul, Brasil

Rosana de Lima Soares I Universidade de São Paulo, Brasil

Tania Hoff I Escola Superior de Propaganda e Marketing, Brasil

REVISÃO DE TEXTO E TRADUÇÃo I Everton Cardoso

ASSISTÊNCIA EDITORIAL E EDITORAÇÃO ELETRÔNICA I Raquel Castedo
COMPós I www.compos.org.br

Associação Nacional dos Programas de Pós-Graduação em Comunicação

Presidente

Erick Felinto de Oliveira

Universidade do Estado do Rio de Janeiro, Brasil erickfelinto@uol.com.br

Vice-presidente

Ana Silvia Lopes Davi Médola

Universidade Estadual Paulista, Brasil

asilvia@faac.unesp.br

Secretária-Geral

Denize Correa Araújo

Universidade Tuiuti do Paraná, Brasil

denizearaujo@hotmail.com 